\title{
An Evaluation of Industrial Facilities Defects in Selected Industrial Estates in Lagos State, Nigeria
}

\author{
Oseghale, G.E..$^{*}$ and Ikpo, I.J. ${ }^{1}$
}

\begin{abstract}
The study appraised the state of industrial facilities in selected industrial estates established between 1957 and 1981 in Lagos State by examining the nature and causes of facilities' defects in the selected industrial estates. The buildings sampled were load bearing sandcrete block wall (1\%), concrete framed structure (83\%) and steel framed structure $(16 \%)$. Data were sourced using structured questionnaire administered on the staff of maintenance department of 35 building materials and plastic manufacturing industries purposively selected and located in 18 industrial estates. Data obtained were analyzed using descriptive statistic. The study found the structural elements of the buildings, i.e. foundations, beams, walls, and floors satisfactory. Using the mean response analysis, the result showed that the most severe factors responsible for industrial facilities' defects were combined effects of geo-climatic factors (2.35), combined effects of biological agencies (2.15), corrosion (1.98), and physical aggression on the facilities (1.71).
\end{abstract}

Keywords: Defects; evaluation; industrial estates; industrial facilities.

\section{Introduction}

Industries represent a segment of the economy concerned with production of goods. Many developed countries such as the United Kingdom and Canada depend significantly on industrial firms for their economic growth and development [1]. There are many different kinds of industries, which are usually grouped into different classes or sectors. The primary industries are agriculture, mining, and raw material extraction, the secondary deals with manufacturing while the tertiary industries have to do with production of services. Manufacturing activities have been shown to impact on the economy of a nation. In developed economies, they account for a substantial proportion of total economic activities. In Nigeria, the sub-sector is responsible for about $10 \%$ of total GDP annually [2].

Ajayi [3] noted that the pattern of the distribution of manufacturing industries at the city level indicated that there was a marked concentration of manufacturing establishments in the Southern part of the country, especially Lagos, Ibadan in the Southwest, and Benin and Port Harcourt in the South-South.

${ }^{1}$ Department of Building, Obafemi Awolowo University, Ile-Ife, Osun State, NIGERIA.

*Corresponding author, e-mail: oseghale2006@yahoo.co.uk.

Note: Discussion is expected before November, $1^{\text {st }} 2014$, and will be published in the "Civil Engineering Dimension" volume 17, number 1, March 2015.

Received 17 February 2014; revised 26 July 2014; accepted 13 September 2014
Other locations of relatively high concentration of industrial establishments are Kano in the North; Enugu, Aba, and Onitsha, in the Southeast. The earliest programme aimed at promoting industrial development in Lagos state was through the establishment of industrial estates. In this regard, the first sets of industrial estates to be established in Nigeria were Apapa and Mushin in 1957, followed by Ikeja in 1959 [4].

The occurrence of defects in industrial facilities will lower its aesthetics value, and total satisfaction of the user of the facility. It will also result in failure of the components, and performance of the facilities. Deterioration takes the form of a gradual decay, systematic or random breakdown of components, or total failure as in the case of collapse [5]. A key determinant of the performance of industrial organization is the state and maintenance of their physical facilities, but these industrial facilities suffer from long periods of shutdown (downtime) for maintenance purposes as a result of deterioration of the facilities [6]. This significantly affects business profitability, effectiveness, and performance of organization. In view of these inadequacies in executing maintenance operations for industrial facilities, there is therefore the need to examine the state of industrial facilities and the factors that causes defects in industrial facilities. The study appraised the physical condition of industrial facilities and the nature and causes of facilities' defects in the selected industrial estates.

\section{Causes of Facilities Defects}

An industrial estate comprises not only the buildings but also services like water, electricity, sewage 
systems of the manufacturing plants. Industrial buildings are constructed using composite building materials such as concrete, timbers, and steel. These materials are subject to one form of deterioration or the other as a result of use and exposure to the environment. In industrial facilities, physical defects are commonly observed in the structure. Obiegbu [7] defined building defect as any irregularity occurring in or on the building elements or fabric, which may lower its strength, durability or utility values. Here, utility covers aesthetics and total satisfaction of the user of the building. The term defect has been defined differently by different authors, to some, it means the shortcoming in design and construction practices, while to others, the inadequacies that arise from normal wear and tear. Defective building means a building that is not performing according to design [8]. Obiegbu [7] classified defect into three areas namely: structural defects, functional defects, and aesthetic defects, while Ikpo [5] classified defects into two broad groups namely: those arising from design and construction flaws (pre-completion agencies), and those resulting from the influence of environmental agencies (post completion agencies). Many factors have been identified to be responsible for defects generation in facilities leading to deterioration individually or collectively. Ilozor et al. [9] showed that some defects caused several other defects, and preventing those defects could eliminate many other defects.

In industrial facilities, different causes can initiate defects (cracks) in material structure. A combinations of several factors or all the factors that initiate cracks in material structures in industrial facilities include: corrosion, mechanical causes (fatigue, welding or vibration, abrasion), stress concentrations due to inappropriate design, geo-climatic agencies, biological agencies, lack of maintenance, and chemical aggression [10-15].

\section{The Design Perspective}

Low and Chong [16] opined that design is the most important driver of building defects as the condition survey showed that design could have prevented at least $66 \%$ of all latent defects found during the early stage of occupancy. Watt [17] observed that inappropriate materials applied to the building and poor expert decision making, caused building defects. Calder [18] found that poorly worded specification and unclear designs often lead to lower construction quality.

Andi and Minato [19] also identified that inadequate information, unawareness, wrong assumptions, and lack of knowledge, alongside other organizational and motivational factors contributed to defects at the design stage.

\section{Construction Faults}

Atkinson [20] found that managerial errors accounted for more than $82 \%$ of all errors committed and that managerial errors are not visible at the construction stage and both clients and designers might not have huge impacts on such defects. Anderson's [21] analysis showed that the distress on the spalling brick-wall that cause vapor infiltration was due to deficiencies in workmanship, material and design.

\section{Lack of Maintenance}

Delaying attending to the problem by indifferent users can heighten the problem of deterioration. When maintenance is ignored (delayed or not executed at all) the effect is to aggravate or to increase the rate of building deterioration from year to year [22-24]. The builder's input to defects after the Defects Liability Period (DLP) is appreciable with an estimated probability of occurrence of 0.733 . The major elements that contribute the highest percenttage to building defects are walls, roof structures and finishes [25].

\section{Corrosion}

When metals are exposed to moisture in the presence of oxygen corrosion take place (rust in the case of ferrous metals). The moisture absorbed causes the surface layer to expand resulting to scaling or spalling from the parent component or element. The loose of spalled surface is referred to as rust, and is composed of hydrated ferric oxide $\left(2 \mathrm{Fe}_{2} \mathrm{O}_{3} .3 \mathrm{H}_{2} \mathrm{O}\right)$ and ferrous carbonate ( $\left.\mathrm{FeC} 0\right)$. Corrosion is accelerated by the presence of industrial gases in the atmosphere within the industrial neighborhoods [26].

Sulphur dioxide is generated by the burning of fuel, and its concentration in the atmosphere is greatest in large industrial areas. Sulphur gases, which dissolve in rainwater, still rank as the most aggressive corrosive substance of some metals and cause some stones to blister or to spall. Sulphate also cause the breakdown of mortar in block-walls, resulting in crack [7].

\section{Physical Aggression}

Abrasion caused either by pedestrians or equipment continuously passing over surface of floor (timber, concrete). Concrete surface, particularly industrial floors, are subjected to wear. Resistance of concrete to abrasion is difficult to assess because the damaging effects depend on the exact cause of wear [26] 


\section{Geo-climatic Agencies}

Building materials and components are subjected to the effects of a number of agencies, which influence adversely their durability and performance, and thereby have major bearing on the possibility of their premature failure. These cover solar radiation, wind, moisture (from the ground, condensation, and driving rain), soil movement [6,27].

Solar radiation causes thermal expansion, which in buildings manifest as thermal expansion cracks in brickwork, block-work, and concrete, if the ends are restrained. Most building materials are opaque, and are, therefore, susceptible to attack by radiations [5]. Temperature changes cause dimensional changes in materials particularly when the coefficient of expansion is high as for example with aluminum and plastics [7]. These changes cause stresses which, if not accommodated, can exceed the strength of some materials and cause distortion or rupture. Rainfall on a heated surface applies severe quenching shock. The frequency, direction, intensity and special composition of solar radiation adversely affect building, structures and generate some defects.

Moisture is the principal agent of deterioration and is probably also the agent with the greatest influence on the properties of materials. It can exist in the form of solid (snow and hailstones), liquid (rain) or vapor [26].

Rains over industrial neighborhoods, for instance, combine with some atmospheric gases to form weak acids. Gases such as carbon dioxide would produce carbonic acid, which has the potential of attacking metallic elements like roofing sheets that are directly exposed to it [5]. Corrosion is accelerated by the presence of industrial gases in the atmosphere [28 cited in 5]. Most of the metallic roofs covering in industrial neighborhoods are commonly observed to be affected by corrosion.

The atmosphere consists of inorganic dust particles. The dirt also contains some soluble salts which are deposited on buildings and causes adverse effects on appearance and increase the corrosion rate of metal surfaces and the deterioration of some stone surfaces. Brumaru [24], also include atmospheric pollution as agent of building decay, especially in industrialized urban areas.

Wind could cause physical damage on poorly secured roof structures, the roof may be blown off or have the structural members damage on the leeward side due to compression, the effects are more significant with increasing height and exposure of the facilities [5].

\section{Biological Agencies}

Attack by rodents, insects, fungi, algae and plants may cause serious deterioration in various parts of a building [26]. Rodents may cause considerable damage to timber and other organic material. Insect attack is generally confined to timber, but some other materials derived from organic fibres or pulp may also be affected. Fungi attack occurs only in the presence of sufficient persistent moisture. Fungi are parasitic and attach themselves to surfaces which supply nutrients.

\section{Research Method}

The study population is primarily the maintenance staff of 35 building and plastics manufacturing industries registered with the manufacturers association of Nigeria and located within the selected industrial estates in Lagos state. Maintenance staff comprises technical and administrative staff of maintenance department, maintenance supervisors, and facilities maintenance managers.

Data collected for this study were primary quantitative and qualitative in nature. Data collected also included the physical condition and functionality of the building elements/components, manufacturing plant, driven equipment, mechanical and electrical services equipment, and factors responsible for facilities defects.

The primary data collected are in two categories. The first category consists of those collected through questionnaires administered on the staff of maintenance departments, while the second category consists of personal observation on the physical condition of the industrial facilities.

\section{Sample Frame}

The sample frame covers all the industrial estates in Lagos. Twenty two industrial estates have been identified in Lagos State based on information on directory of manufacturing companies prepared by Lagos State Ministry of Commerce, Industry, and Tourism.

\section{Sample Size}

A total of 22 industrial estates were identified based on information from the directory of manufacturing companies. The sample size used followed Sediary [29], i.e.

$\mathrm{n}=\mathrm{n}_{1} /\left(1+\mathrm{n}_{1}\right) / \mathrm{N}$

Where $\mathrm{n}$ is the sample size;

$\mathrm{n}_{1}=\mathrm{S}_{1} / \mathrm{V}^{2}$;

$\mathrm{S}_{1}=\mathrm{Pq}$ 
In which $\mathrm{N}$ is the total estimated population; and $\mathrm{V}$, the standard error of the sampling distribution $=$ $0.05, \mathrm{~S}_{1}$, the maximum standard deviation in population, $\mathrm{P}$ is the proportion of population element that belong to a defined class (assumed to be 0.5), $\mathrm{q}$ is the population proportion without the required class.

$q=(1-P)$

with a total error $=0.1$ at a confidence level of $95 \%$. From Equations 3 and $4, \mathrm{~S}_{1}=0.25$, then the sample size for the industrial estates will be (Equation 1)

$\mathrm{n}=\left(0.25 / 0.05^{2}\right) /\left(1+\left(0.25 / 0.05^{2}\right) / 22=18\right.$

A total of 322 companies are located within the industrial estates in Lagos state. For homogeneity of data, only building materials and plastic manufacturing industries were purposively selected.

Of the 54 companies in this category on the register, using Sediary equation (Equation 1), the sample size was 35 firms.

For uniformity and convenience, ten sets of questionnaire were administered to the maintenance staff in each of the 35 industrial firms selected randomly.

\section{Data Collection Instruments}

The questionnaire were administered on the staff of maintenance department, and the interview guide was used to conduct interviews with unit/departmental heads of the maintenance department of the building and plastic manufacturing companies in the selected industrial estates in Lagos State. The questionnaires are designed in such a way to be a combination of close and open-ended questions. The open-ended questions allowed the respondents to give detailed answers in cases where their intentions or experiences cannot be easily calculated into a few options.

The questionnaire is divided into two sections. The first section (Section A) deals with the background of respondents and general information about the companies, while the second (Section B) asks questions on the various physical condition of the facilities.

\section{Facilities Assessment Procedure}

A condition assessment of all the selected facilities was conducted. The assessment was performed by visiting each of the selected sites and visually inspecting all the facilities. When possible, the facilities were assessed during operation. Examples of components/elements that were assessed in the facilities include the following:
- Mechanical Systems: Air conditioning.

- Interior Surfaces: Internal walls, floors, ceilings, etc.

- Structural Damage: Visual inspection of the structural integrity of the building.

- Fire Safety: Availability of fire extinguishers, presence of smoke and flames or any surface which is extremely hot, fire alarm, etc;

- Electrical: Major electrical equipment, electrical panels, check for the exposed wire.

- Sewage System

- Drinking Fountains

- Roofs

- Rest rooms

- External surfaces,

- Windows/Doors/Gate and Fence, and

- Overall cleanliness of the surrounding.

Descriptive statistical techniques such as frequency distribution and percentages, mean, were used on the physical condition of the facilities, and causes of defects.

The frequency distribution was used to analyze the general information on the personal data of the maintenance staff, the users and the characteristics of the industrial facilities.

\section{Data Analysis and Discussion}

Questionnaires were distributed to staff of maintenance department in the industrial firms sampled in the selected industrial estates in Lagos State. A total of 350 copies of the questionnaire were administered with $60.17 \%$ response rate (i.e. 213 copies). These were used for the analysis.

To ensure that the objectives of the research were achieved, general information concerning the industries were collected. The information included the date of establishment of the company, profession of the respondents, nature of business set-up, respondents working experience, number of permanent employees, registration of company with corporate affairs commission, type of construction, and functional use of the buildings.

Table 1 shows the profession of the respondents sampled. This shows that the respondents cut across the various professionals who possess the required knowledge about the subject under survey to contribute meaningfully to this research.

Table 2 shows the respondents working experience. This shows that the respondents sampled have the relevant experience in the industries to be able to respond to the questions asked. 
Table 1. Profession of Respondents

\begin{tabular}{lcr}
\hline & Frequency & Percent \\
\hline Electrical engineering. & 68 & 31.9 \\
Architecture & 7 & 3.3 \\
Building & 6 & 2.8 \\
Civil engineering & 16 & 7.5 \\
Mechanical engineering & 83 & 39.0 \\
Material engineering & 8 & 3.8 \\
Administrative officers & 25 & 11.7 \\
\hline Total & 213 & 100.0
\end{tabular}

Table 2. Respondents Working Experience

\begin{tabular}{lcr}
\hline & Frequency & Percent \\
\hline less than 2 years & 26 & 12.2 \\
2 to 4 years & 60 & 28.2 \\
5 to 7 years & 37 & 17.4 \\
8 to 10 years & 58 & 27.2 \\
Above 10 years & 32 & 15.02 \\
\hline Total & 213 & 100.0 \\
\hline
\end{tabular}

\section{Professional Assessment of the Nature of Industrail Facilities Defects}

The facilities were professionally assessed by inspecting each facility and noting the physical and operational defects of the building elements and components. Maintenance records of the facilities were checked and assessed. The research found that areas for offices and where customers were received, were regularly maintained. The reason given was that the firms want to continually maintain a good profile before their customers. Physical observation of the building sampled showed that there were minor defects in the blocks used for offices and the areas where customers were received. The areas specifically used for factory (i.e. for production) were not well maintained. These areas of the structures were defaced, cracks were noticed on the walls and floors with much wears on finish (Figures 1 to 4). The structural elements of the buildings sampled (beams, columns, walls, floors) were found to be in good condition. Exterior wall condition was rated the lowest in this category. The respondents were also asked to assess and rate the physical conditions of the facilities.

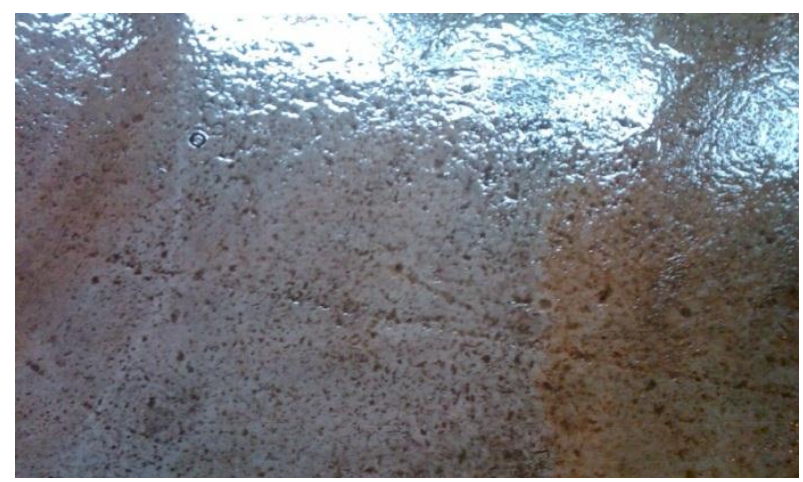

Figure 1. Wearing of Floor Finish due to Abrasion

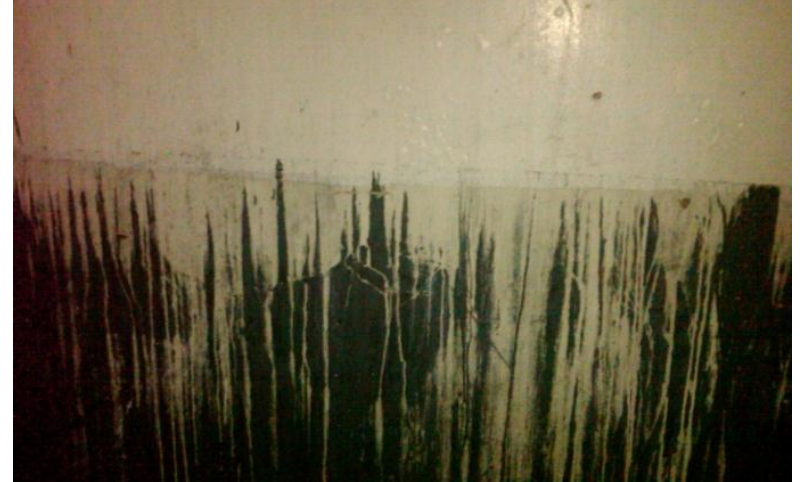

Figure 2. Showing Stains on Wall

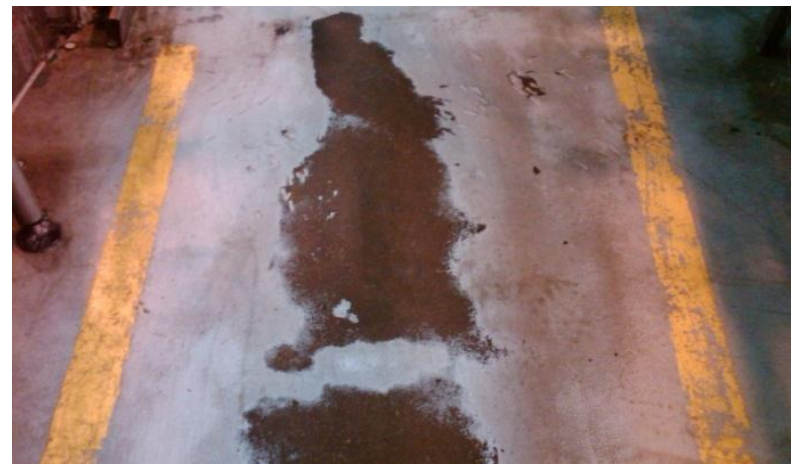

Figure 3. Showing Wearing of Floor Finish

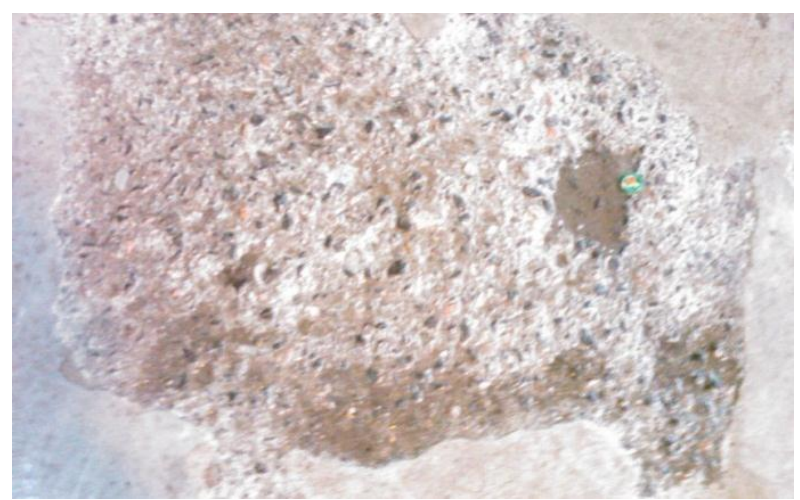

Figure 4. Showing Flaking of Floor Finish

\section{Physical Condition of Industrial Facilities as Perceived by Maintenance Staff}

Maintenance staff was asked to assess the state of the physical condition of industrial facilities. Ten of such facilities that were assessed were building elements and components. The other facilities were grouped into manufacturing plant, driven equipment and generators. The respondents were asked to indicate their perception on a 5-point scale ranging from 1-very bad, 2-bad, 3 average, 4-good, 5-very good.

The respondents ranked the rating of the physical condition of the facilities. The facilities with the best 
condition carry a ranking equal to one (1) and other rankings follow the same chronological order.

Sum Weighted Value (SWV) for each physical condition was obtained by adding the product of each number of responses and the weighted value given to each rating (Equation 5).

$\mathbf{S W V}=\sum_{i=1}^{5} x_{i} y_{i}$

Where $x_{i}$ is number of respondents to rating $\mathrm{i}, y_{i}$ the weight assigned to a value $(\mathrm{i}=1,2,3,4,5)$. This was obtained by dividing each respondent SWV by the number of respondents (213).

Table 3 shows the computed Relative Importance Index (RII) for physical condition of industrial estate sampled. Relative importance index were calculated to show the rating of the physical conditions of the industrial facilities sampled. The results revealed that the structural elements of the building have the highest rating, followed by floors, doors, windows, and fire safety equipment conditions respectively. Also the manufacturing plants and the driven equipment had the same rating, while generators were poorly rated.

\section{Factors Responsible for Facilities Defects}

Records of the maintenance departments in the industries sampled were checked in order to assess the suggested factors responsible for industrial facilities defects. Six of such major factors were identified as design deficiencies, construction faults, corrosion, physical aggression, geo-climatic agencies (solar radiation, moisture, wind, frost, and soil condition), and biological agencies (attack by rodents, insects, fungi, and plant growth).

Mean response analysis (Equation 6) was calculated for the factors responsible for industrial facilities defects.

Table 3. Physical Conditions of Industrial Facilities as Perceived by Maintenance Staff

\begin{tabular}{lcc}
\hline \multicolumn{1}{c}{ Facilities } & RII & Ranking \\
\hline Structural conditions (Beam /column) & 0.56 & 1 \\
Floors & 0.53 & 2 \\
Door condition & 0.53 & 2 \\
Window condition & 0.52 & 3 \\
Fire safety equipment & 0.51 & 4 \\
Plumbing condition & 0.50 & 5 \\
Electrical condition & 0.50 & 6 \\
Roof condition & 0.48 & 6 \\
Interior wall condition & 0.46 & 7 \\
Exterior wall condition & 0.33 & 8 \\
Plant and Equipment: & & \\
(a) manufacturing plants & 0.51 & 1 \\
(b) driven equipment & 0.51 & 2 \\
(c) generator & 0.47 & 3 \\
\hline
\end{tabular}

Table 4. Factors Responsible for Industrial Facilities Defects from Professional Observation and Maintenance Records

\begin{tabular}{lccc}
\hline \multicolumn{1}{c}{ Factors } & Mean & Ranking & $\begin{array}{c}\text { Overall } \\
\text { Ranking }\end{array}$ \\
\hline $\begin{array}{l}\text { Geo-climatic agencies: } \\
\text { (i) Soil conditions }\end{array}$ & 2.357 & 1 & \\
(ii) Wind & 2.099 & 2 & \\
(iii) Moisture & 1.845 & 3 & 1 \\
(iv) Solar radiation & 1.728 & 4 & \\
(v) Frost & 1.704 & 5 & \\
Biologic agencies: & & & \\
(i) Attack by rodents & 2.150 & 1 & 2 \\
(ii) Attack by insects & 2.113 & 2 & \\
(iii) plants growth & 2.080 & 3 & \\
(iv) Attack by fungi & 2.066 & 4 & \\
Corrosion & 1.977 & & 3 \\
Physical aggression & 1.709 & & 4 \\
Construction faults & 1.498 & & 5 \\
Design deficiencies & 1.413 & & 6 \\
\hline
\end{tabular}

Mean Score $=\left(5 n_{5}+4 n_{4}+3 n_{3}+2 n_{2}+1 n_{1}+0 n_{0}\right) /\left(n_{5}+\right.$ $\left.n_{4+} n_{3+} n_{2}+n_{1+} n_{0}\right)$

where $n_{0}$ is the number of respondents who answered "no occurrence" or "no impact", n 1 who answered "very low occurrence" or "little impact", $\mathrm{n}_{2}$ who answered "low occurrence" or "fairly critical impact", $\mathrm{n}_{3}$ who answered "medium occurrence" or "high impact", $\mathrm{n}_{4}$ who answered "high occurrence" or "more impact", and $n_{5}$ who answered "very high occurrence" or "most impact", The facilities with the highest mean score carry a ranking equal to one (1) and other ranking follow the same chronological order. The results of the findings is shown in Table 4.

The impact of geo-climatic agencies was calculated individually as a group and the result shows that the effect of soil condition was ranked number one, followed by wind, moisture, solar radiation, and frost. Mean response analysis for biological agencies shows that attack by rodents were ranked number one followed by insect attack, plant growth, and attack by fungi. The result of the suggested factors responsible for industrial facilities defects show that the combined effects of geo-climatic factors ranked highest, followed by the combined effects of biological factors, next to that were corrosion, then physical aggression, while design deficiencies ranked lowest.

\section{Discussion of Findings}

Over $80 \%$ of the industrial firms sampled have operated for sufficient number of years to have been involved in the different maintenance operations. The respondents cut-across professionals such as architects, quantity surveyors, builders, electrical engineers, civil engineers, mechanical engineers, and material engineers. Others were administrative officers (accountants, business administrators etc). 
About $60 \%$ of the maintenance staffs were mainly mechanical and electrical engineers. About $70 \%$ of the manufacturing firms were limited liability companies and were mostly multinationals and well established. The buildings sampled were constructed of concrete framed structures, only $6 \%$ of the industrial firms sampled have separate blocks for offices, and were above one floor. Physical observation of the buildings sampled shows that there were minor defects in the blocks used for offices and the areas where customers were received. The areas specifically used for factory (i.e. for production) were not well maintained, in these areas the structures were defaced, cracks were noticed and with much wears on the finish.

Majority of the respondents were satisfied with the structural elements of the buildings, i.e. foundations, beams, columns, walls, and floors. The respondents were asked to rate their level of satisfaction on the physical condition of the building elements and components. The result showed that $78 \%$ of the respondents were satisfied with the exterior wall conditions, over $70 \%$ of the respondents were satisfied with the doors/windows condition, while $60 \%$ of the respondents were satisfied with the electrical fittings, and about $55 \%$ of the respondents were satisfied with the floors conditions.

The respondents were also asked to rate their level of satisfaction with the functionality of the physical facilities. Over $65 \%$ of the respondents rated the structural fabrics of the building high in functionality, while about $50 \%$ of the respondents rated the electrical services high, over $65 \%$ rated the functionality of the mechanical services high. A higher percentage of the respondents believe that the fire safety equipment was functioning optimally.

The research went further to measure the strength of each of the identified factors responsible for industrial facilities defects. The results show that the most severe factors responsible for defects were: combined effects of geo-climatic agencies; combined effects of biological agencies; corrosion; physical aggression; and construction faults.

\section{Conclusion}

The study was focused on appraising the state and maintenance of industrial facilities. The state of maintenance of industrial facilities (buildings) was rated $65 \%$ in performance. Structures and fabrics were rated $70 \%$ in functionality and their physical condition, while facilities in the production areas suffer neglect and were poorly maintained, as the walls were defaced and much wear on the floor finishes. The study revealed that the most severe factors responsible for defects were: combined effects of geo-climatic agencies, combined effects of biological agencies; corrosion; physical aggression; and construction faults.

The state of physical facilities in the manufacturing/ production areas of the industries is a very critical issue to be tackled by industrial facilities management and chief executive officers with utmost urgency. The management of industrial firms should be made to understand that the way facilities are maintained has positive, mostly indirect effects on business performance and organization effectiveness.

\section{References}

1. Olaye, S., Data Collection Strategy Covering Small Units (country practice-Nigeria). National Bureau of statistics, Nigeria, A Paper Presented at Expert Group Meeting on Industrial Statistics, New York 19-23 September 2005.

2. National Bureau of Statistics, Manufacturing. The Federal Republic of Nigeria, 2009.

3. Ajayi, D.D., Recent Trends and Patterns in Nigeria's Industrial Development. Council for the Development of Social Science Research in Africa, African Development, 32(2), 2007, pp. 139-155.

4. Ministry of Commerce and Tourism, Directory of Manufacturing Companies Lagos State, Ministry of Commerce and Tourism. Lagos State Nigeria, 1998.

5. Ikpo, I.J., Building Maintenance Management, Oron, Manson Publishing Company, 2006.

6. Oseghale G.E., Facilities Maintenance Management Strategy in Selected Industrial Estate in Lagos State, Nigeria. Unpublished M. Phil Thesis, Department of Building, Obafemi Awolowo University, Ile Ife, 2012.

7. Obiegbu, M.E., Factors Influencing the Defects and Performance of Builder, Journal of the Nigerian Institute of Building, 2003, pp. 53-61.

8. Abdulmohsen, A, Sadi, A., and Al-shihah, M., The Effect of Faulty Design on Building Maintenance, Journal of Quality in Maintenance Engineering. 3(1), 1997, pp. 29-39.

9. Ilozor, B.D, Okoroh, M.I, and Egbu, C.E., Understanding Residential House Defects in Australia from the State of Victoria. Building and Environment, 39(3), 2004, pp. 327-337.

10. Herrera J.M, Spencer, P.R, Tavin, P.M., and Stafford, S.W., A Failure Analysis Case Study Structural Steel Sign Post Collapse, Material Characterization, 34(1), 1995, pp. 57-61.

11. Kuznicka, B. and Strozyk, P., Failure Analysis of Disintegrator Beaters, Engineering Failure Analysis, 13(1), 2006, pp. 155-162. 
12. Parida, N. and Tarafder, S., Failure Analysis of Turbo-Generator of a $10 \mathrm{~mW}$ Captive Power Plant, Engineering Failure Analysis, 8(3), 2001, pp. 303-309.

13. Guangje, P., Zhengwei, W., Zongguo, Y., and Ruixiang, L., Strength Analysis of Large Centrifugal Pump Case, Engineering Failure Analysis, 16(1), 2009, pp. 321-328.

14. Ost, W., De Baets, P., and Van Wittenberghe, J., Failure Investigation and Redesign of Piston and Pump Shafts, Engineering Failure Analysis, 16(4), 2009, pp. 1174-1187.

15. Jenabali-Johromi, S.A., Javadpour, S., and Gehisari, H.H., Failure Analysis of Welded Joints in a Power Plant Exhaust Flue, Engineering Failure Analysis, 13(4), 2006, pp. 527-536.

16. Low, S.P. and Chong, W.K., Construction Quality Evaluation and Design Parameters for Preventing Latent Defects in Buildings. Proceeding Joint International Symposium of CIB Working Commissions, Singapore, 2004, pp. 554566.

17. Watt, D., Building Pathology: Principle and Practice, Blackwell Science, Oxford, U.K., 1999.

18. Calder, D.A.J., Construction Quality Auditing, Journal of Management Engineering, 13(6), 1997, pp. 26-28.

19. Andi and Minato, T., Representing Casual Mechanism of Defective Designs: A System Approach Considering Human Errors, Construction Management Economics, 21(3), 2003, pp. 297-305.

20. Atkinson, A.R., The Pathology of Building Defects: A Human Error Approach, Engineering Construction and Architectural Management, 9(1), 2003, pp. 53-61.
21. Anderson, L.M., Spalling Brick-Material, Design or Construction Problem, Journal of Performance Construction Facility, 13(4), 1999, pp. 163-171.

22. Al-Sultan, K.S., Maintenance in Saudi Arabia: Needs and Recommendations for Improvement, Journal of Quality in Maintenance Engineering, 2(4), 1996, pp. 5-16.

23. Olubodun, F.O., An Empirical Approach to the Evaluation of Factors in Local Authority Housing Maintenance Requirements in the City of Manchester, Unpublished Ph.D Thesis, Department of Surveying, University of Salford, Salford, England, 1996.

24. Brumaru, M., Need and Strategy in Housing Rehabilitation: The Romanian case, in Ural, $O$. Abrantes, V. \& Tedeu, A. (eds) Ibid. 3, 2002, pp. 1975-1984.

25. Ikpo, I.J., The Builders' Liability Beyond the Defects' Liability Period, Civil Engineering Dimension, 7(1), 2005, pp.16-21.

26. Ikpo, I.J., Building Maintenance Culture: The Nigerian Experience, The Professional Builder, 2008, pp. 12-18.

27. Son, L.H. and Yuen, G.C.S., Building Maintenance Technology, Macmillan, London, 1993

28. Skoulikidis, T.N., Corrosion Problem in Greece, Corrosion, Prevention and Control, 26(3), 1979, pp. 5-8.

29. Sediary, S.T., Management of Conflict; Public Sector Construction in Saudi Arabia. International Journal of Project Management, 12(3), 1994, pp.143-151. 